\title{
ARTE VISUAL: UM ESPAÇO DE APRENDIZAGEM NO ENSINO DE GEOGRAFIA
}

\author{
Rita de Lúcia de Almeida Ferreira Guimarães ${ }^{1}$ \\ Adriana Maimone Aguillar ${ }^{2}$
}

\begin{abstract}
Resumo: $O$ ensino de Geografia destinado aos alunos do Ensino Fundamental II urge por ressignificação e novas experiências. O mundo mudou e a Educação escolar encontra dificuldades para acompanhar tais mudanças. Nessa perspectiva a Arte visual é uma possibilidade para auxiliar no desenvolvimento dos conteúdos, interagindo com a realidade na contemporaneidade, a qual se pauta sobremaneira nas Artes visuais. Portanto nosso objetivo é apresentar a Arte visual como recurso metodológico capaz de promover na sala de aula o desenvolvimento de práticas de ensinoaprendizagem de forma prazerosa, despertando a atenção e curiosidade para os conteúdos da Geografia. Trata-se de levantamento bibliográfico acerca do uso da Arte visual no ensino de geografia, com auxílio do referencial teórico baseado em Vigotski sobre a imaginação. A imaginação poderá ser promovida por determinadas imagens com potencial para desenvolver a criatividade de crianças e adolescentes, quer seja na área das artes ou dos estudos científicos. No "espaço" da Arte visual o docente encontra um importante aporte didático, anunciando uma educaçáo renovada e articulada com a geraçáo atual, promovendo a interação entre a realidade dos alunos, a realidade da escola e a realidade atual no que tange às mídias e redes sociais.
\end{abstract}

Palavras-chave: Arte visual. Didática. Ensino de geografia.

\section{VISUAL ART: A SPACE FOR LEARNING IN TEACHING GEOGRAPHY}

\begin{abstract}
Geography teaching for elementary school students urges for new meaning and new experiences. The world has changed and school education finds it difficult to keep up with these changes. In this perspective, visual art is a possibility to assist in the development of content, interacting with the reality in contemporary times, which is especially based on visual arts. Therefore,
\end{abstract}

1 Discente do curso de Licenciatura em Geografia, Universidade Federal do Triângulo Mineiro, Uberaba/MG. E-mail: rita.guimaraes@uftm.edu.br

2 Professora Doutora do Departamento de Educação do Instituto de Educaçáo, Letras, Artes, Ciências Humanas e Sociais, Universidade Federal do Triângulo Mineiro, Uberaba/MG. E-mail: adriana.aguillar@uftm.edu.br 
our goal is to present visual art as a methodological resource capable of promoting in the classroom the development of teaching-learning practices in a pleasant way, arousing attention and curiosity for the contents of Geography. This is a bibliographic survey about the use of visual art in the teaching of geography, with the aid of the theoretical framework based on Vigotski about imagination. Imagination can be promoted by certain images with the potential to develop the creativity of children and adolescents, whether in the field of arts or scientific studies. In the visual art "space" the teacher finds an important didactic contribution, announcing a renewed and articulated education with the current generation, promoting the interaction between the students' reality, the school reality and the current reality with respect to the media and networks social.

Keywords: Visual art. Didactics. Geography teaching.

\section{INTRODUÇÃO}

O ensino de geografia abarca uma pluralidade de saberes, exigindo do docente uma postura que fomente, desperte o interesse e atraia a atenção dos alunos em sala de aula para que o conhecimento se concretize. A forma como o docente age em sala de aula tem grande relevância para o aprendizado do aluno. Essa forma de agir pauta-se na didática que para Corsino (2015) é uma resposta responsável àqueles a quem o ensino se dirige.

A geração de hoje, difere-se das gerações anteriores. Santos (2008) destaca que a geração atual vive o sistema de técnicas representado pela chegada da técnica da informação, da informática e da eletrônica, permitindo a convergência dos momentos e assegurando a simultaneidade das açôes. De acordo com Santos (2008), a possibilidade oferecida pelo meio técnico informacional encontra alicerces na produção de imagens e do imaginário.

Nessa conjuntura, a geração dos alunos de hoje está imersa em um arsenal de imagens que facilita toda informaçáo, mas que na visão de muitos professores "rouba" a atenção dos mesmos e dificulta a apreensão do conhecimento escolar. Em experiência de estágio foi possível observar que a maioria alunos pouco lê, pouco pesquisa e tem dificuldades em fazer análises, são alunos muito visuais, rápidos, informados, mas muitas vezes desinteressados pelo saber escolar.

Daí, percebe-se a necessidade do uso de "ferramentas" que possam auxiliar na superação do desinteresse dos alunos, mormente pelo ensino de Geografia devido ao denso conteúdo que lhe é inerente e, que chamem a atenção dos mesmos para a necessidade e importância que a disciplina exerce sobre a realidade social na qual estáo inseridos. A escolha dos recursos didáticos a serem trabalhados é de fundamental importância para a construção do processo cognitivo.

Em nosso entendimento, essa questão torna-se mais delicada ao docente com atividades no Ensino Fundamental II, considerando que nesse nível do ensino os alunos encontram-se na fase da adolescência, marcada por transformaçôes biológicas e comportamentais. Para boa parte deles a escola, a priori, é um espaço de encontros, eventos e quase sempre, em último caso, de aprendizado escolar. Diante dessa conjuntura, existem muitos desafios a serem superados na condução e desenvolvimento das aulas de Geografia. 
Portanto nosso objetivo é apresentar a Arte visual aqui representada pelo uso de charges, memes, mapas pictóricos, desenhos, caricaturas, dentre outros como recurso metodológico capaz de promover na sala de aula, o desenvolvimento de práticas de ensino-aprendizagem de forma a estabelecer um diálogo mais prazeroso e efetivo com os alunos da nova geraçáo. A partir do uso da Arte visual, acreditamos despertar a atenção e curiosidade dos alunos para os conteúdos da Geografia.

Este trabalho destina-se aos professores de Geografia do ensino fundamental II, com o intuito de fomentar a utilização da Arte visual em suas dinâmicas de ensino, como recurso didático apto a contribuir de forma significativa ao desenvolvimento da aprendizagem, uma vez que esse tipo de arte instiga a curiosidade, podendo estimular o desejo pelo saber escolar. Espera-se que os resultados contribuam com o docente de forma efetiva, transformando as relações professor-aluno e as práticas pedagógicas em momentos de ludicidade, prazer e aprendizado.

A Arte visual possui um espaço de signos e significados capazes de despertar nos alunos o interesse pelo estudo por sua abrangência de manifestaçôes artísticas, permitindo uma infinitude de possibilidades que auxiliam no desenvolvimento dos conteúdos, pois nesse espaço encontramos um arsenal artístico de grande relevância para a formação dos alunos. Para Santos e Chiapetti (2011, p. 177):

A utilização da charge/cartum/quadrinhos no ensino de Geografia pode ser uma tarefa muito prazerosa [...] Esse "brincar" com a realidade não significa reduzir a seriedade do conteúdo trabalhado, mas representa uma forma mais agradável de compreender a realidade. Outro fator interessante é o desenvolvimento/ despertar do senso crítico nos alunos, aspecto de extrema importância na análise do espaço geográfico, além do fato de partirmos de uma realidade concreta e contextualizada na análise da charge.

O conceito de Arte visual é intrínseco ao conceito de visualização, daquilo que se vê, remetendo-nos a um dos objetos de estudo da geografia: a paisagem, que tal como a arte visual, náo se resume apenas naquilo que se vê, na imagem por si só, mas "conta" histórias e carrega marcas, refletindo processos, movimentos e tempos históricos da realidade de determinado momento, por possuir linguagem própria e exercer o fascínio da leitura pelos sentidos.

Concordamos com Ferraz (2009) ao afirmar que o geógrafo que iniciar o processo de estudo e reflexão a partir de imagens acerca de determinantes espaciais, terá indício de sucesso, pois as imagens contribuem para o ser humano melhor localizar-se e orientar-se no mundo.

Contudo importante ressaltar que não há um método ou receita pronta e acabada que auxilie na oferta de ensino de qualidade e suas dimensóes linguísticas, cognitivas e pessoais, mas a necessidade constante por uma prática pedagógica que valorize o ensinar e transforme os processos educacionais com o propósito de integrar o conhecimento teórico e o prático, e que valorize a ludicidade de forma orientada para fazer a diferença. Não afirmamos todavia, que a Arte visual seja por si só capaz de resolver todos os desafios do momento, mas como recurso didático pode auxiliar sobremaneira o trabalho docente, dado o potencial de atraçáo da atenção. 
A proposta consiste ao mesmo tempo, em buscar formas de utilizar tal recurso para resgatar a habilidade do adolescente em realizar pesquisas e análises mais profundas das informaçóes na aquisição do conhecimento, ou seja, inserir a arte não somente pela arte, mas sim e principalmente a arte pela edificação do saber. Desse modo não temos a intençáo de prescrever elementos que melhor possam ser utilizados em sala de aula, contudo citaremos alguns que pensamos ser um espaço de aprendizado potente para o ensino de geografia.

\section{A DIDÁTICA AMPLIA AS POSSIBILIDADES DE SUCESSO DA AÇÃO DOCENTE}

A didática não pode ser considerada de modo limitado e simples, meramente um conjunto de práticas, mas um campo do conhecimento capaz de transformar metas pedagógicas em finalidades de ensino, com intuito de ampliar as possibilidades de sucesso da açáo docente. Para Corsino (2015 p.410) "Buscar formas de pensar o ensino significativo e criativo é um dos maiores desafios da didática." Com essa autora entendemos que para o ensino ser transformador, necessário se faz constante reflexão, crítica, diálogo com diferentes áreas, prospecção e engajamento social. Corsino (2015) refere-se à didática como ato responsivo, ato esse expresso na prática social realizada entre professores e alunos. Isso implica dizer que o que ensinamos e o modo como ensinamos é o reflexo do nosso modo de perceber o mundo. Ainda em Corsino (2015), temos a linguagem em todas as suas formas: verbal, não verbal e ou multimodal (aqui encontramos as imagens) como parte constituinte da didática. $\mathrm{Na}$ concepçáo dessa autora no que concerne à linguagem (para nós visual), há um empobrecimento nas escolas pelo uso estritamente instrumental das manifestaçóes artísticas, um espaço reduzido de troca e de efetiva expressão, evidenciando um desconhecimento da arte e de sua funçáo criadora. A arte possibilita a experiência estética, entendida como abertura à sensibilidade, sem a qual incorremos no risco do vazio da continuidade acrítica. Conforme afirma a autora "[...] a arte é o lugar do inesperado[...]" (GERALDI, 2010, p.116 apud CORSINO, 2015, p. 410), aludindo ao trabalho estético com a linguagem, concepçáo essa que nos coloca diante do novo, em situação de poder ser afetado pelo outro por meio do conhecimento. Por fim Corsino (2015) também ressalta os estudos de Vigotski, como contribuiçôes relevantes para a educação e para a didática em especial. Segundo Corsino (2015) em Vigotski, o desenvolvimento do sujeito é propiciado pelo trabalho colaborativo e interativo. Nessas circunstâncias, uma didática compromissada com o desenvolvimento dos estudantes, considera imprescindível "[...] o trabalho coletivo e o lugar do professor na organização do grupo, na disponibilização de recursos e neste processo colaborativo." (CORSINO, 2015, p. 411).

Por sua vez, Cordeiro (2009, p.98) admite que "Pensar o ensino e a aprendizagem em termos da relaçáo pedagógica implica admitir a complexidade da sala de aula e considerar as questóes de ensino de um ponto de vista dinâmico". Portanto o professor atento preocupa-se com uma aula atrativa, buscando uma 
prática que crie mecanismos para estimular a participaçáo de todos de maneira ativa no processo da aprendizagem.

Mas "[...] muitas formas de ensinar hoje não se justificam mais, e tanto professores como alunos temos a clara sensação de que muitas aulas convencionais estão ultrapassadas.” (MORAN, 2006, p. 11 apud SANTOS e CHIAPETTI, 2011, p.174 apud). Muitos professores, no entanto, ainda hoje, utilizam a didática tradicional meramente prescritiva, como fundamento para suas práticas pedagógicas, não se dando conta de que vivemos outra geração, com alunos bem diversos das geraçóes anteriores. Mantemos a cultura de que na sala de aula o aluno náo pode ter momentos de prazer, acabando por privá-lo de sua espontaneidade, onde conforme Moreira e Schwartz (2009) estáo imersos em regras a serem formalizadas de acordo com objetivos a serem atingidos, ficando tais momentos de prazer restritos ao recreio. Principalmente nas escolas públicas, mas também nas privadas o ensino muitas vezes não consegue alcançar os aspectos básicos da aprendizagem, a exemplo da escrita e leitura.

Em experiências de estágio, observamos uma geração de alunos mais acelerados, questionadores e dinâmicos. Isso nos remete a um descompasso entre a realidade atual dos alunos e a realidade das escolas. Grande parte da nova geraçáo comunica-se via mensagens instantâneas, sem regras, sem formalidades, mais rápido, com poucos caracteres, palavras suprimidas. Para muitos deles, seguir regras e ou normativas gramaticais dá trabalho, exige tempo e muito estudo. É uma geração em sua maioria impaciente, com pouca capacidade de concentraçáo para abordagens que demandem mais tempo de concentração e aprofundamento do raciocínio. Portanto as cartilhas do século anterior tornaram-se insustentáveis para a nova geração. $\mathrm{O}$ perfil do aluno de hoje náo se enquadra mais nas práticas docentes do ensino das geraçóes passadas, exigindo do docente novas formas de pensar a sua prática pedagógica no intuito de melhor trabalhar os conteúdos, contemplando o novo e ressignificando os objetivos de ensino.

Santos e Chiapetti (2011) explicam que os alunos carecem de habilidade para ler, analisar e interpretar a leitura de imagens, tamanho o hábito da leitura apenas de palavras escritas. Consideraçáo essa que igualmente pudemos observar em experiências de estágio, desta vez na sala dos professores. Percebemos que existe na fala de alguns professores, queixas de que muitos alunos ainda têm dificuldades para fazer uma redação e ou resolver operaçôes simples de matemática por não conseguirem interpretar o que está sendo pedido, chegando ao final da educação básica com sérias deficiências que são refletidas quando na concorrência às vagas para adentrarem ao ensino superior. Em se tratando da Geografia, para compreender e organizar o espaço geográfico em sua totalidade, a didática pode oferecer alternativas metodológicas renovadas que de acordo com Mello (2012, p.24) "[...] possibilitem o acesso, a interação e a apropriaçáo dos conceitos geográficos, por parte dos alunos."

Dentre as várias ferramentas metodológicas, encontramos a Arte Visual que no contexto do século XXI, interage e dialoga com tudo e todos, pois o século XXI apresenta um forte apelo das cores, dos desenhos, dos virtuais, da Arte Visual. Essa 
lógica foi observada em experiência de estágio quando na aplicação de uma prova aos alunos do $6^{\circ}$ ano do ensino Fundamental II em escola estadual do município de Uberaba - MG, onde havia uma questão que solicitava desenhar a Rosa dos Ventos. No geral os alunos náo sabiam responder as questóes dissertativas, mas o desenho da rosa dos ventos todos acertaram, além disso alguns desenhos pareciam verdadeiras obras de arte. Outro momento que se evidenciou tal situaçáo onde os alunos mostram ser mais visuais, foi na apresentação do mapa pictórico da culinária de Portugal. A que país se referia não souberam dizer, mas que o tema do mapa era sobre cultura alimentar, a maioria dos alunos percebeu. Nesse momento perceberam inclusive, o significado de mapas pictóricos, que são mapas que atribuem informaçóes espaciais por meio de desenhos figurativos.

Tais experiências demonstram que o contato com a arte possibilita o conhecimento de outras formas de expressão, sentimentos e opiniôes. Nesse sentido a Arte visual se destaca cada vez mais ao desenvolver práticas exitosas na educaçáo, favorecendo a organização pedagógica. A arte cria um ambiente de possibilidades ao aluno onde ele aprende brincando, analisando e pesquisando a partir do ensino. A potencialidade da arte visual no ensino da geografia pode ser percebida ao se estabelecer uma linguagem compatível com aquela que os adolescentes estão acostumados, e assim ter maior chance de afetar o aluno e estabelecer um diálogo mais efetivo, podendo despertar a visão crítica por meio da leitura das imagens.

\section{A ARTE FOI UMA DAS PRIMEIRAS FORMAS DE COMUNICAÇÃO ENTRE OS SERES HUMANOS}

"Antes mesmo de saber escrever, o homem expressou e interpretou o mundo em que vivia pela linguagem da arte. A caverna, com sua umidade rochosa, foi o ateliê do homem pré-histórico." (PSICOSQUE e GUERRA, 1998, p.34 apud CAVA, 2014, p.04). Segundo Cava (2014), a arte surgiu desde a Antiguidade, quando os homens da Pré-história utilizavam a arte rupestre, ou seja, desenhos feitos em cavernas, onde por meio de tais figuras, representavam a caça. Cava (2014) destaca que a palavra "arte" teve muitos significados ao longo da história, alguns pesquisadores consideravam-na como forma de criação, enquanto outros acreditavam ser uma maneira de imitar; a partir do século XIX tinha o objetivo de retratar a beleza; já no século XXI referia-se principalmente às artes plásticas, entendida como um conjunto de manifestaçóes artísticas expressas na pintura, escultura, desenho, arquitetura, artesanato, teatro, fotografia, cinema, dança, design, arte urbana, dentre outros, estando intrinsecamente atrelada ao conceito de visualizar. Ainda em Cava (2014) atualmente a arte também pode ser produzida com ferramentas tecnológicas, criadas a partir de programas de computador, abrangendo o caráter estético e visual do objeto artístico. Portanto em nosso entendimento a vertente artística visual pode auxiliar os alunos na compreensão e criação de novos elementos que valorizem tanto o viés estético quanto o princípio cognitivo implícito na imagem dentro do contexto onde a mesma está integrada. 


\section{ARTE VISUAL VOLTADA AO ENSINO DE GEOGRAFIA}

Fiori (2007) afirma que a arte e o desenho são recursos à cartografia. Segundo esse autor:

O tema é de grande interesse, porque a arte consegue reter o elemento sensorial. O prazer proporcionado por uma ilustração vai além de seu conteúdo, pois possibilita ao espectador combinar, juntar, derivar algo pela justaposiçáo de experiências ou aspectos de uma única experiência. O prazer que uma representação é capaz de nos proporcionar é originado por motivos e imagens que estimulam a lembrança de sensaçôes de cheiro, gosto, audição[...] (FIORI, 2007, P. 131).

Santos e Chiapetti (2011, p.170) confirmam que a "Geografia tem sido vista por muitos alunos como uma disciplina enfadonha, desconectada da realidade e que exige muita memorização de conteúdos”. Entretanto, articulada à Arte visual, a Geografia pode ganhar um novo brilho, proporcionando ao aluno desfrutar de momentos de prazer ou divertimento ao mesmo tempo em que aprende, superando o desinteresse pela disciplina que de enfadonha passa a excitante, pois despertado o interesse, o aluno é capaz de superar desafios, inclusive de memorização, mormente com o avanço da tecnologia que possibilita desenvolver várias atividades envolta das artes.

Para a Geografia o viés artístico permite analisar elementos da paisagem perceptíveis aos nossos sentidos, capazes de revelar os modos culturais de uma sociedade em diferentes espaços e tempos, possibilitando diferentes interpretaçóes, significados e representaçóes nela inseridos. Portanto ensinar geografia a partir da Arte visual uma oportunidade inovadora de ensino-aprendizagem que permite ao aluno vivenciar experiências novas, uma vez que atualmente o potencial informacional do mundo está afeito principalmente à comunicação visual.

A Geografia em seu cerne explica a lógica da produção agrária, a transformaçáo dos espaços na cidade, a distribuiçấo dos movimentos sociais e a estrutura geomorfológica da Terra. Seu objetivo principal reside no zoneamento e planejamento das açôes humanas sobre o espaço e manutenção da vida em sociedade. Nesse contexto a estética da imagem pode parecer banal para um analfabeto geográfico (indivíduo ignorante dos conhecimentos geográficos), porém para o geógrafo a imagem carrega importantes informaçóes acerca de como a geografia está presente no nosso dia a dia e pode influenciar direta ou indiretamente na nossa qualidade de vida. Em Dantas e Morais (2007, p. 2):

[...] o geógrafo está imerso no mundo das imagens, estejam elas grafadas em suportes diversificados, estejam elas disponíveis no grande cenário que é a paisagem. Ensinar a olhar as imagens do mundo se constitui o desafio do professor de geografia.

Igualmente Ferraz (2009) concorda que as imagens da arte capacitam o homem entender o real a partir do olhar, principalmente "Para o geógrafo, que tem no olhar a paisagem o ponto de partida do processo de estudo e reflexão sobre os 
determinantes espaciais da sociedade.” (FERRAZ, 2009, p. 30). Esse autor refere-se ao sentido do olhar, como sentido voltado ao intelecto, explicando que:

Esse olhar significa ampliar o sentido de paisagem à geografia, para ir além e aquém do entendimento usual que se tem dela, identificando as sombras e os processos não aparentes que se imbricam naquilo que se mostra como vidente/ evidente [...] Eis o que o geógrafo tem como tarefa. [...] Exercitar a leitura das "qualidades estéticas" do olhar geográfico sobre a paisagem a partir da análise das pinturas é um caminho possível e altamente enriquecedor para o processo de discussão entre as ordenaçóes espaciais da sociedade, do cotidiano e do mundo como um todo, em suas diversas expressóes paisagísticas [...] Aprender a ver pinturas pode auxiliar numa melhor leitura do espaço, assim como uma análise geográfica dos quadros pode enriquecer a compreensáo deles. E isso o geógrafo, pesquisador e/ou professor, precisa exercitar por excelência. (FERRAZ, 2009. p.31).

\section{ALGUNS ELEMENTOS DA ARTE VISUAL QUE PODEM CONTRIBUIR PARA O ENSINO DE GEOGRAFIA}

Diante desse cenário, iniciaremos nossa discussão pelas fotografias que de acordo com Dantas e Moraes (2007) fazem a interseção entre a técnica e a intuição, permeando a razáo e a emoção, constituindo uma ferramenta singular na prática do ensino de geografia. Pois a fotografia nos revela um instante da realidade compactada na imagem que representa; evidenciando naquilo que vemos, um modelo "reduzido" de tal realidade, compondo um mosaico que envolve processos de conhecimentos do todo que precede as partes.

As fotografias, especialmente no que concerne à compreensão do urbano, possibilitam entender o papel da cidade enquanto espaço de contradiçóes que abarca um rol de "atividades setoriais especificamente realizadas por formaçóes urbanas" (PENA, "Função das cidades"; Brasil Escola, [202-]), pela forma como as diversas imagens fotográficas induzem a questôes problematizadas no conteúdo geográfico.

As imagens retratam momentos históricos que são concebidos muitas vezes, como única fonte de referência a determinados acontecimentos que levam à compreensão do conhecimento. Elas exprimem os processos espaciais que a geografia analisa. Reconhecer a importância das imagens na produção do conhecimento geográfico, é valorizar a participação das representações pictóricas na disciplina, exemplificado na figura a seguir: 
Figura 1 - Análise geográfica de uma fotografia

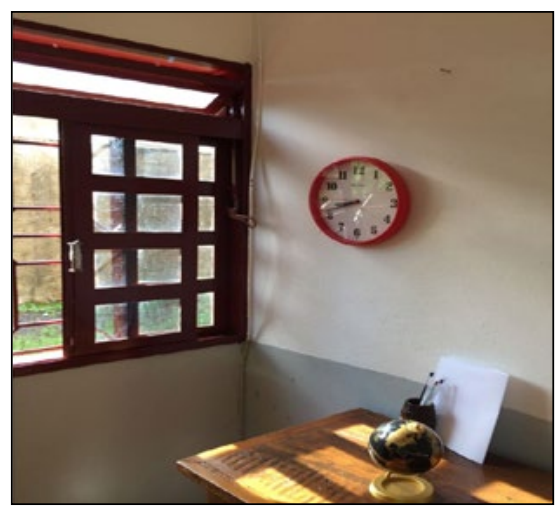

Fonte: Acervo pessoal maio 2019

A fotografia acima reflete o tempo (relógio) materializado no espaço (parede) no sentido figurado e literal do conceito da palavra geografizar, para explicar a dinâmica das açóes no espaço que não se desvincula do tempo e, da dinâmica superficial da terra. Essa dinâmica reflete a importância da Geografia, suas contribuiçóes, objetivos e utilidade. $\mathrm{E}$ ainda conforme o guia do livro didático (BRASIL, PNLD 2016, p. 14):

Entender o porquê dos acontecimentos em diferentes locais do mundo ressignifica o próprio lugar do estudante. Compreender os lugares convida os estudantes a manterem a aproximação com as categorias do tempo e da memória não como mera cronologia (estudar o passado para entender o hoje), mas para realçar o vínculo inseparável entre espaço e tempo. Os espaços têm memória. O espaço é o acúmulo de tempo. $\mathrm{O}$ tempo se materializa nos espaços.

É possível identificar os pontos cardeais na imagem através dos raios solares que estão incidindo no interior do ambiente. Como o sol nasce ao leste e seu trajeto é leste/oeste, do lado esquerdo da imagem está o Leste, local de onde vêm os raios solares. Esse é um importante detalhe que nos ajuda a vislumbrar um melhor proveito da luz solar quando no planejamento da construção de nossas casas. É possível igualmente inferir o tempo histórico pela figura do relógio. Trata-se de um relógio analógico de parede, portanto contemporâneo aos dias de hoje. A escolha de um relógio analógico para fins utilitários, pode denotar questóes socioeconômicas (mais acessível que um relógio digital) e ou de estética (o analógico possui maior variedade de modelo do que o digital devido aos vários tipos de fontes numéricas). Por fim, o muro que aparece do lado de fora da janela, denota que a construção é de procedência do meio urbano, assim como o design da janela: uma janela moderna com grades acopladas, demonstrando a precaução com a segurança, consequência da violência atrelada ao desenvolvimento urbano.

Outro elemento primordial na disciplina de geografia são os mapas que consistem em representar espaços geográficos por meio de imagens construídas pelo 
homem para reproduzir parte ou toda realidade espacial. Entretanto para alguns alunos do ensino fundamental II, os mapas constituem-se em algo complexo não tão simples de serem interpretados. Todavia Fiori (2007) propóe o uso da pictografia que se configura como uma forma alternativa de comunicação cartográfica, informando atraçôes naturais e ou culturais de um determinado espaço e aborda tanto intençóes estéticas quanto representativas, aproximando assim a definiçâo de cartografia da definição de design, da comunicação e da arte. Os símbolos pictóricos expressos nos mapas em geral são um bom exemplo de como trabalhar a cartografia sem exigir do aluno uma gama de conteúdos para caracterizar um continente, país, estado ou cidade, representando suas relaçóes espaciais e ou relaçóes sociais. Os mapas pictóricos podem ser utilizados como um suporte à cartografia, onde o aluno aprende brincando a interpretar mapas simples passando gradativamente à leitura de mapas mais complexos. O professor pode propor a confecção de mapas para estimular o interesse e a pesquisa envolvidos na análise do espaço pretendido ou exigir uma leitura mais dinâmica e detalhada dos mapas pictóricos presentes nos livros didáticos, incitando o aluno desenvolver sua percepção geográfica sobre o potencial de leitura dos mapas, conforme o exemplo abaixo:

Figura 2 - Mapa pictórico da Antártica

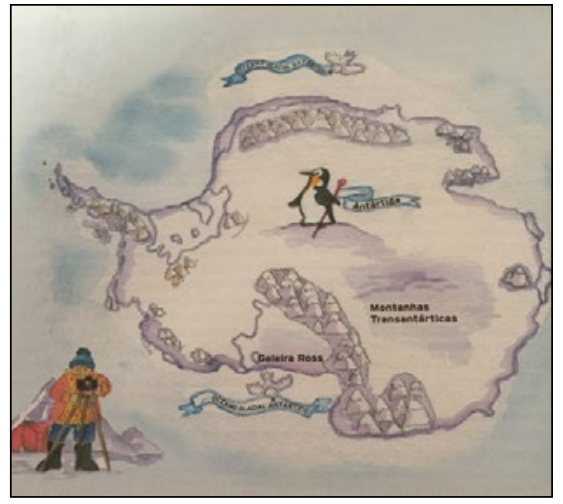

Fonte: SAMPAIO, Fernando dos Santos. Para Viver Juntos:Geografia, $7^{\circ}$ ano: anos finais: ensino fundamental, 2015.

O mapa pictórico acima retrata a Antártica, o continente mais frio do mundo, característica essa bem evidente no mapa. Pela imagem do mapa é possível perceber que náo há populaçáo, apenas a presença de um pesquisador, denotando que a Antártica é um continente inóspito. Há também a presença de um pinguim demonstrando o tipo de fauna da regiáo. Enfim os mapas pictóricos possuem elementos que nos permitem fazer várias análises acerca dos principais aspectos que caracterizam um determinado espaço. Esses tipos de representaçóes, colaboram com a memorização de conteúdos abstratos que vêm rapidamente à lembrança do aluno, contribuindo para a apreensão das informações contidas no mapa. 
Dentro do arsenal artístico visual, temos também as charges e caricaturas muito veiculados nas redes sociais para retratarem conteúdos ligados aos aspectos humanos da Geografia, interessantes para serem utilizados em sala de aula como instrumentos de reflexão e perspectivas de determinado momento histórico. Segundo Arrigoni (2011), a charge caracteriza-se pelo aspecto humorístico, sendo muito utilizada em sátiras, as quais descrevem elementos voltados às relaçóes econômicas, políticas, sociais e culturais. Em Silva (2016) entendemos que a charge exprime uma única ideia por meio de uma imagem onde "[...]costuma haver a associação da linguagem verbal e não verbal." (SILVA. Charge, cartum, tirinha e caricatura: entenda as diferenças, 2016). As caricaturas, por sua vez, visam o exagero na retratação de algo com o sentido de provocar o riso na maioria das vezes, geralmente são utilizadas como instrumento para exercer função social com intenção satírico-moralizante, especialmente como meio de luta e crítica religiosa, assim como política e social também. Dessa forma, explorar charges e caricaturas em sala de aula é concorrer para uma aprendizagem mais atraente e contextualizada com a atualidade. Arrigoni (2011, p. 2073) concorda:

Assim destaca-se o papel didático da imagem, o papel de formar uma consciência crítica no leitor, que não é mais receptor passivo da mensagem passada, mas é incentivado a interpretar a ideia proposta, a pensar sobre o assunto e a concordar com aquela ideologia ou náo. Por isso, as charges e caricaturas buscam muito mais do que simplesmente fazer rir. Seu objetivo é inculcar no expectador sua reflexão e seus valores, transmitidos pelo desenhista.

Igualmente as tirinhas são concebidas como outro elemento artístico que muito atrai a atenção dos alunos do ensino fundamental pelo caráter multimodal e por fazer parte da nova tendência de comunicação, uma vez que o século XXI é caracterizado principalmente pelo aporte das imagens. Aqui Silva (2016) traz a tirinha como "[...] uma sequência de quadrinhos que geralmente faz uma crítica aos valores sociais." (SILVA. Charge, cartum, tirinha e caricatura: entenda as diferenças, 2016) geralmente narrando uma pequena história. Esse tipo de arte, além de possuir aspectos lúdicos, carrega ao mesmo tempo, princípios subentendidos na forma como se manifestam, quer seja denotando um objeto, um conceito ou uma crítica, constituindo uma forma de aprendizado divertida. Os textos multimodais consistem na união de elementos alfabéticos e imagéticos, ou seja, na linguagem verbal escrita e visual. Portanto a tirinha constitui-se segundo diferentes modos de representaçáo e, assim como as charges, propicia ao leitor desenvolver a habilidade de produzir inferências, por meio da articulação dos diferentes recursos semióticos, conforme nos mostra a tirinha a seguir: 
Figura 3 - PIB e Renda Per capta

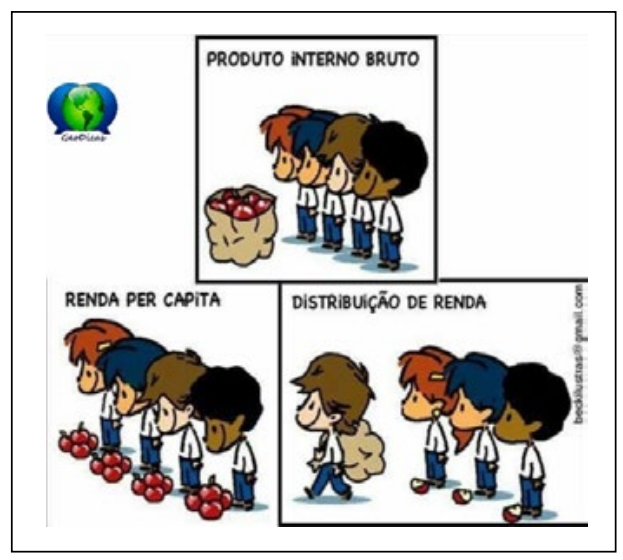

Fonte: https://br.pinterest.com/

A tirinha traz o conceito de PIB e renda per capta de forma irônica, problematizando conteúdos sociais, políticos e econômicos atrelados aos aspectos humanos da geografia. A forma figurativa como a tirinha representa tais conceitos e aguça o senso crítico expresso na imagem.

Temos ainda como o mote do momento, os memes que tal como os elementos anteriormente citados, caracterizam-se pela associação de uma imagem e um diálogo ou frase denotando e ressignificando um contexto social, possibilitando aos alunos desenvolverem uma visão crítica da realidade. Valle (2018) afirma que "[...] os memes produzidos nas redes sociais se valiam das histórias clássicas dos contos de fadas para produzirem textos irônicos[...]" (VALLE, Memes ajudam a desenvolver interpretaçáa de texto e pensamento crítico, 2018) e discutir papéis preestabelecidos na sociedade. O termo Meme é de origem grega, significando imitação e:

[...] é bastante conhecido e utilizado no "mundo da internet", referindo-se ao fenômeno de "viralizaçáo"de uma informação, ou seja, qualquer vídeo, imagem, frase, ideia, música e etc, que se espalhe entre vários usuários rapidamente, alcançando muita popularidade (PORTAL SERVIÇOS SGPTI. SIGNIFICADOS. SIGNIFICADO DE MEME, abril 2015).

Geralmente cumprem uma função política e questionam estereótipos que vão além das piadas, como no exemplo: 
Figura 4 - O uso de agrotóxicos na agricultura

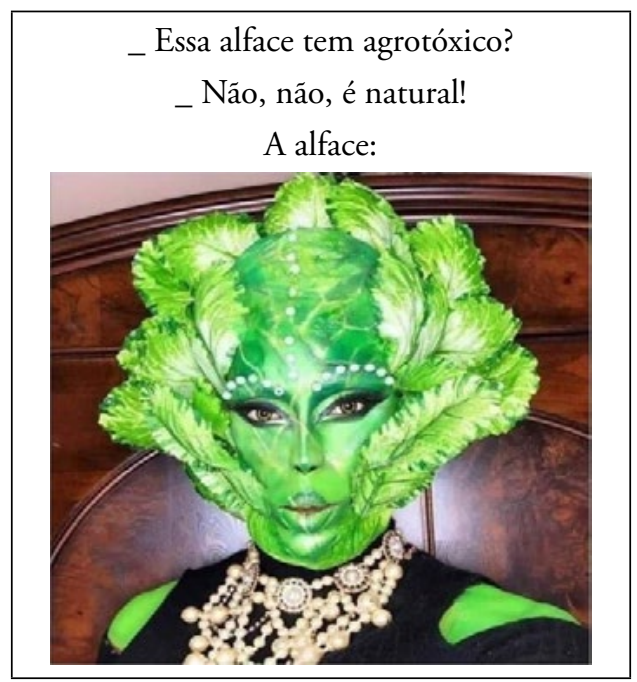

Fonte: Geografia em Memes@Geoemmemes

O meme acima traz no cerne de sua discussão qual o papel dos agrotóxicos na agricultura, o uso indiscriminado e as especulaçóes sobre a verdade por trás dos mesmos. A alface representada pelo meme indica que a mesma sofreu uma mutação. Um mote que revela a contradição entre o alimento natural e o alimento cultivado com agrotóxico. Questóes de grande impacto que devem ser discutidas em sala de aula, para motivar a especulação sobre temas controversos de modelos preestabelecidos por Instituiçóes que carregam no discurso o uso de certos elementos como imprescindíveis, sem esclarecer as consequências de seu uso, a exemplo do agronegócio que justifica o uso do agrotóxico na agricultura em grande escala para aumentar a produção e acabar com fome no mundo.

Dentre os diversos elementos que compóem as artes visuais, acentuamos o desenho que para Fiori "reflete a emoção da mensagem de maneira muito mais rápida do que as palavras, quase sempre garantindo sem interrupçóes a atenção do usuário em uma apresentação. Mesmo assim, o desenho é um dos recursos mais negligenciados" (WOLFGRAM, 1994, p. 104 apud FIORI, 2007, p.135) conservando algumas semelhanças ou expressóes equivalentes do fenômeno representado no mundo real.

Buscando ressaltar o valor do desenho, apontamos ainda o psicólogo Lev Vigotski que vê nessa arte (desenho) importância significativa para o desenvolvimento cognitivo. Para Vigotski (2014) ao desenhar a criança "pensa no objeto de sua imaginaçáo como se estivesse descrevendo-o." (VIGOTSKI, 2014, p.99). O adolescente, por sua vez, tenta reproduzir a realidade por meio do desenho, com vistas ao aperfeiçoamento no sentido mais pleno do termo. O desenho e as cores despertam algo no adolescente a ser desvendado ampliando horizontes, adquirindo uma nova linguagem que o permite expressar nas imagens a imaginação criativa. 
O desenho comunica ideias e invoca códigos e convençôes simbólicas, colocando em prática a concepção de cognição e valorização de experiências já assimiladas, evidenciando os mecanismos de percepção na interação cultural. As dimensóes artísticas, a partir dos pressupostos da psicologia sócio-histórica, contribuem para a expressão e organização da emoção e da imaginação. Cava (2014) a esse respeito cita Vigotski para explicar que ao imaginar, a criança incorpora diferentes papéis, podendo ora ser um adulto, ora ser uma criança ou mesmo um animal ou herói. Na situação de imaginação a criança vai além do comportamento habitual, transcendendo a um nível superior.

Vigotski (2014) aponta o drama, o desenho, a leitura e a escrita criativa como modos de expressão que a criança e também o adolescente no desenvolvimento elabora e a escola deve promover, de modo a potencializar o desenvolvimento e a aprendizagem, onde a atividade criativa faz parte das realizaçóes humanas originando o novo e a imaginação. Para Vigotski (2014) a cultura é criada por meio da imaginação e criação humana e, os objetos do nosso cotidiano são concretizações fruto de nossa imaginação. Ele ressalta que a capacidade de criação nas crianças e adolescentes tem importância primordial para o desenvolvimento e, portanto, deve ser estimulada. Quanto mais experiências acumuladas, mais a atividade criadora e imaginação são estimuladas.

Por fim, Vigotski (2014, p.12) ressalta: "A conclusão pedagógica que podemos tirar daqui é a necessidade de ampliar a experiência da criança se quisermos proporcionar-lhes bases suficientemente sólidas para sua atividade criativa."

Para Barroco (2014) a produção vigotskiana, com base na teoria históricocultural, e sua relevância para o desenvolvimento humano, possui notoriedade entre os estudiosos da psicologia e da educaçáo no campo da arte, a qual altera o humor imediato dos indivíduos, desenvolvendo outras possibilidades humanas, podendo em um simples contato, transcender a uma nova organização psíquica. No mesmo contexto temos Camargo e Bulgacov (2008) onde o real livre de rigidez, "[...]passa a ser algo que se pode olhar a partir de vários ângulos, para encontrar a melhor forma de compreendê-lo." (CAMARGO e BULGACOV, 2008, p. 472), levandonos a descobrir formas até então inusitadas de perceber o mundo. Gonçalves (2015) explicando a teoria histórico-cultural ressalta que "Aos conhecimentos espontâneos, o sujeito pode estabelecer novas relaçóes com os conhecimentos escolares, formando nexos conceituais mais complexos." (GONÇALVES, 2015, p. 4).

Náo raro, encontramos alunos que melhor expressam no desenho aquilo que não conseguem expressar na linguagem escrita. Barros (2013) acredita que criatividade faz parte da condiçáo humana, defendendo outras formas de literacia, como o desenho, que descreve qualidades de um mundo difícil de se explicar discursivamente, mas experienciado sensivelmente de modo diverso ao ensinoaprendizagem. Santos (2013) afirma que "Os desenhos revelam muito sobre a natureza do pensamento humano e a sua capacidade de resolver problemas." (SANTOS, 2013, p. 82). Trabalhar com desenhos, é trabalhar os aspectos visuais da memória e do pensamento, podendo ser naturais (espontâneos) ou construídos, 
diferentemente da escrita. $\mathrm{O}$ desenho auxilia o aluno a transformar o abstrato em algo "tangível" à sua compreensão. O aluno ao produzir desenhos é capaz de expressar sua ideologia, valores e conceitos; é o que nos mostra o desenho abaixo:

Figura 5 - Chuvas Orográficas

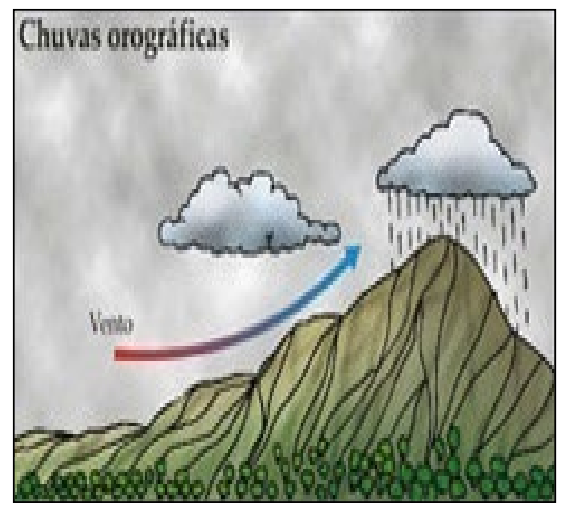

Fonte: todamateria.com.br

No exemplo é possível representar o fenômeno físico do conceito de chuvas orográficas, conceito esse menos comum à realidade dos alunos. "Denominadas de "chuva de relevo", esse tipo de precipitação ocorre quando há um impedimento (seja montanha, serras ou escarpas) que barra a massa de ar úmida" (TODA MATÉRIA, GEOGRAFIA, Tipos de Chuva, set 2019). A apreensão do conceito de chuvas orográficas ou de relevo, por parte dos alunos pode ser facilitada pela representaçáo do desenho. $\mathrm{O}$ desenho nos permite representar fenômenos e objetos "em movimento".

Por tudo isso, entendemos o desenho como ferramenta de grande relevância nas aulas de geografia, uma Arte visual simples, capaz de representar temas complexos que as palavras por si só talvez não consigam exprimir de forma táo inteligível e espontânea!

\section{CONSIDERAÇÓES FINAIS}

Os recursos didáticos prescritivos e "conteudistas" de outrora tornaramse pouco eficientes diante da nova realidade, não mais contemplando o perfil do aluno do século XXI. O momento histórico contemporâneo encontra-se imerso no mundo das imagens (contexto bastante distinto da geração anterior), lidamos portanto com uma geração de alunos visuais, cuja educaçáo tem se mostrado despreparada, enfrentando grandes dificuldades em despertar a atenção e interesse dos alunos do século XXI. Portanto em face das mudanças atuais, necessário se faz que a didática, especialmente no que tange aos recursos metodológicos, na mesma conjuntura se atualize, buscando novos métodos, novos autores, novas experiências. 
Mormente no contexto atual, a Arte Visual torna-se importante aliada no ensino-aprendizagem voltado à Geografia. Sua contribuição na organização do trabalho pedagógico para o ensino fundamental II leva à reflexáo e pesquisa, por promover um trabalho interdisciplinar, possibilitando uma aprendizagem significativa. Tal arte desponta como um espaço de aprendizagem que nos permite acurar o olhar geográfico dos alunos, habilitando-os a estabelecer várias relaçôes, quais sejam mesmo diante de uma imagem "vazia", onde a leitura do banal pode transformar-se em intelectual; pois a beleza verdadeira da arte está muitas vezes implícita e consiste na intenção de quem a cria, essencialmente quando é capaz de transformar uma imagem corriqueira em um arsenal de saberes para quantos o possuam.

Para tanto foram discutidos e exemplificados alguns elementos artísticos capazes estimular o senso crítico e reflexivo dos alunos, sua capacidade de organização e atenção menos fugaz, facilitando a construção do saber sem tornar o aprendizado algo maçante e enfadonho. Dentre os elementos discutidos o desenho ganha destaque, pois conforme citado em experiência de estágio, a arte de desenhar aguça os sentidos dos alunos, proporcionando-lhes prazer ao representar aquilo que muitas vezes náo conseguem pelo uso somente das palavras escritas ou mesmo faladas.

$\mathrm{Na}$ Arte Visual o docente encontra um importante aporte didático, anunciando uma educaçáo renovada e articulada com a geração atual, promovendo a interação entre a realidade dos alunos, a realidade da escola e a realidade atual no que tange às mídias e redes sociais.

\section{REFERÊNCIAS}

ARRIGONI, Mariana de Mello. Debatendo os conceitos de Caricatura, Charge e Cartum. III Encontro Nacional de Estudos da Imagem 03 a 06 de maio de 2011 Londrina - PR Disponível em: <http://www.uel.br/eventos/eneimagem/anais2011/ trabalhos/pdf/Mariana\%20de\%20Mello\%20Arrigoni.pdf>. Acesso em 14 jan 2020.

BARROCO, Sonia Mari Shima; SUPERTI, Tatiane. Vigotski e o estudo da psicologia da arte: contribuições para o desenvolvimento humano. Psicologia \& Sociedade. Vol.26 n.1 Belo Horizonte Jan./Apr. 2014.

BARROS, Joana Polônia De. A concepçáo do desenho no ensino das artes visuais e currículo diversificado. Universidade Lusófona de Humanidades e Tecnologias. Escola de Comunicação, Arquitetura, Artes e Tecnologias da Informação. Lisboa, Portugal, 2013.

BRASIL, Ministério da Educaçấo. PNLD 2017: Geografia - Ensino fundamental anos finais. Brasília, DF: Ministério da Educação, Secretaria de Educação Básica, 2016. p. 14. Disponível em: <https:/www.fnde.gov.br/index.php/programas/programas-do-livro/pnld/ guia-do-livro-didatico/item/8813-guia-pnld-2017>. Acesso em 19 jan 2020. 
CAMARGO, Denise de; BULGACOV, Yara Lúcia Mazziotti. A perspectiva estética e expressiva na escola: articulando conceitos da psicologia sócio-histórica. Psicol. estud. vol. 13, n. 3, 2008. p.467-475.

CAVA, Laura Célia Sant’Ana Cabral. Ensino de Arte e Música. Londrina:UNOPAR, 2014.

CORDEIRO, Jaime. Didática. 1a ed. São Paulo: Contexto, 2009.

CORSINO, Patrícia. Entre Ciência, Arte e Vida: a didática como ato responsivo. Educação \& Realidade. Porto Alegre, vol. 40 n. 2. p. 390 - 419. abr./jun.2015.

DANTAS, Maria Eugênia; MORAIS, Ione Rodrigues Diniz. O ensino de Geografia e a imagem: universo de possibilidades. IX Colóquio Internacional de Geocrítica. UFRGS. Porto Alegre, 2007.

FERRAZ, Cláudio Benito Oliveira. Geografia: o olhar e a imagem pictórica. ProPosições, Campinas, v. 20, n. 3 (60), p. 29-41, set./dez. 2009. Disponível em: <http:// www.scielo.br/pdf/pp/v20n3/v20n3a03.pdf>. Acesso em 03 jun 2019.

FIORI, Sérgio Ricardo. MAS PARA O TURISMO E A INTERATIVIDADE: Proposta teórica e prática. São Paulo, 2007. Disponível em: <https://www.teses.usp.br/teses/ disponiveis/8/8135/tde-03042008-143859/publico/TESE_SERGIO_RICARDO_ FIORI.pdf>. Acesso em 12 jan 2020.

Geografia em Memes. Disponível em: <https://twitter.com/geoemmemes>. Acesso em 17 jan 2020 .

GONÇALVES, Amanda Regina. A TEORIA HISTÓRICO-CULTURAL E O ENSINO DE GEOGRAFIA . XV Encuentro de Geógrafos de América Latina, Universidad de La Havana, Cuba, 2015. Disponível em: <http://observatoriogeograficoamericalatina.org. $\mathrm{mx} /$ egal15/Teoriaymetodo/Geografiahistoricaehistoriadelageografia/06.pdf $>$. Acesso em 11 jan 2020.

MELLO, Marcia Cristina de Oliveira. UMA APROXIMAÇÃO À DIDÁTICA DO ENSINO DE GEOGRAFIA - volume 9 - D22 - Unesp/UNIVESP - 1a edição 2012 graduação em Pedagogia.

MOREIRA, Jaqueline C. Castilho; SCHWARTZ, Gisele Maria. Conteúdos lúdicos, expressivos e artísticos na educaçáo formal. Educ. rev. n.33, 2009. p.205-220.

PENA, Rodolfo F. Alves. "Funçáo das cidades"; Brasil Escola, [202-]. Disponível em: https://brasilescola.uol.com.br/geografia/funcao-das-cidades.htm. Acesso em 15 de janeiro de 2020 .

PINTEREST. Disponível em: <https://br.pinterest.com/pin/31314159885572538/>. Acesso em 03 abril 2020. 
PORTAL SERVIÇOS SGPTI. SIGNIFICADOS. Significado de Meme. Data de atualização: 20/04/2015. Disponível em : <https://www.significados.com.br/meme/>. Acesso em 15 abr 2020.

SAMPAIO, Fernando dos Santos. Para Viver Juntos:Geografia, $7^{\circ}$ ano: anos finais: ensino fundamental. 4. ed. São Paulo: Edições SM, 2015, p. 32.

\section{SANTOS, Clézio. DESENHOS E MAPAS NO ENSINO DE GEOGRAFIA: A} LINGUAGEM VISUAL QUE NÃO É VISTA. Geograficidade | v.3, Número Especial, Primavera 2013. Disponível em: <file:///home/rita/Downloads/Dialnet-DesenhosEMapas NoEnsinoDeGeografia-4734959.pdf>. Acesso em 12 fev 2020.

SANTOS, Milton. Por uma outra globalizaçáo: do pensamento único à consciência universal. 15a edição. Rio de Janeiro: Record, 2008.

SANTOS, R. de C. E. dos; CHIAPETTI, R. J. N. Uma investigaçáo sobre o uso das diversas linguagens no ensino de Geografia: uma interface teoria e prática. Geografia Ensino \& Pesquisa,v. 15, n.3, set./dez. 2011, p. 167-183.

SILVA, Débora. Charge, cartum, tirinha e caricatura: entenda as diferenças, nov 2016. Disponível em: <https://www.estudokids.com.br/charge-cartum-tirinha-e-caricaturaentenda-as-diferencas/>. Acesso em 12 fev 2020.

TODA MATÉRIA: conteúdos escolares. Artigo revisado em 24/09/19. Disponível em: <https://www.todamateria.com.br/tipos-de-chuvas/>. Acesso em 13 jan 2020.

VALLE, Leonardo. Memes ajudam a desenvolver interpretaçáo de texto e pensamento crítico. Instituto Claro. Educação, 2018. Disponível em: <https://www. institutonetclaroembratel.org.br/educacao/nossas-novidades/reportagens/memes-ajudama-desenvolver-interpretacao-de-texto-e-pensamento-critico/>. Acesso em 09 jan 2020.

VIGOTSKI, L.S. Imaginação e criatividade na infância. Tradução do Russo e Introdução: João Pedro Fróis. Revisão Técnica e da Tradução: Solange Affeche. São Paulo: Matins Fontes, 2014. 